The paper is a post-print version of the published article in 2014 Meas. Sci. Technol. 25055110 (http://iopscience.iop.org/0957-0233/25/5/055110). The DOI of the final published paper is (doi:10.1088/0957-0233/25/5/055110). 


\title{
Electrical Impedance Imaging of Water Distribution in the Root Zone
}

\author{
P. Newill ${ }^{1}$, D. Karadaglić ${ }^{2}$, F. Podd ${ }^{1}$, B.D. Grieve ${ }^{1}$, T.A. York ${ }^{1 *}$ \\ ${ }^{1}$ School of Electrical \& Electronic Engineering, University of Manchester, UK \\ ${ }^{2}$ School of Engineering and Built Environment, Glasgow Caledonian University, UK \\ *Corresponding author : t.a.york@manchester.ac.uk
}

\begin{abstract}
The paper describes a technique that is proposed for imaging water transport in and around the root zone of plants using distributed measurements of electrical impedance. The technique has the potential to analyse sub-surface phenotypes, for instance drought tolerance traits in crop breeding programmes. The technical aim is to implement an automated, low cost, instrument for highthroughput screening. Ultimately the technique is targeted at in-field, on-line, measurements. For demonstration purposes the present work considers measurements on laboratory scale rhizotrons housing growing maize plants. Each rhizotron is fitted with 60 electrodes in a rectangular array. To reduce electrochemical effects the capacitively-coupled contactless conductivity (C4D) electrodes have an insulating layer on the surface and the resistance of the bulk material is deduced from spectroscopic considerations. Electrical impedance is measured between pairs of electrodes to build up a two-dimensional map. A modified electrical model of such electrodes is proposed which includes the resistive and reactive components of both the insulating layer and the bulk material. Measurements taken on a parallel-plate test cell containing water confirm that the C4D technique is able to measure electrical impedance. The test cell has been used to explore the effects of water content, compaction and temperature on measurements in soil. Results confirm that electrical impedance measurements are very sensitive to moisture content. Impedance fraction changes up to $20 \%$ are observed due to compaction up to a pressure of $0.21 \mathrm{~kg} / \mathrm{cm}^{2}$ and a temperature fraction sensitivity of about $2 \% /{ }^{\circ} \mathrm{C}$. The effects of compaction and temperature are most significant under dry conditions. Measurements on growing maize reveal the changes in impedance across the rhizotron over a period of several weeks. Results are compared to a control vessel housing only soil.
\end{abstract}

Keywords capacitively-coupled contactless conductivity, electrical impedance imaging, root zone monitoring, soil moisture 


\section{INTRODUCTION}

There is growing interest in exploring the use of soil-based measurements around the root zone of plants to inform crop-based studies. One possibility is to infer plant health and growth characteristics from moisture distribution around the plant root system. The technical aim of the present work is to implement an automated, low cost, instrument for high-throughput screening based on the measurement of electrical impedance. The scientific aim is to use the acquired data to determine water movement which in turn will provide information on root function and structure.

Soil is created from particles of broken rock caused by weathering and erosion. There is no single definitive description of soil as it can vary widely, with each 'type' of soil having merits according to the particular application. Soil is classified by the ratio of sand, silt, clay and organic matter, both living and dead, to determine the texture. Characterisation is often determined using the soil texture triangle in which the ratio of the three main particle components determines the classification [Brady 1974, White 1979]. The difference in size between the smallest clay particles to coarse sand and gravel can vary as much as 10,000 times. The soil can be classified by performing a particle size distribution to determine the ratio of sand, silt and clay particles. Soils with larger pores, such as a sandy loam, will hold less water than a clay soil and drain quicker. Although clay soils hold more water, the pores are much smaller and the suction required to remove this water is greater. As stone content increases within a soil sample it can hold less water, making crops more susceptible to drought. The structure of the soil is defined by the way in which the four components are physically arranged and this is readily changed. The way the soil is "worked" has a substantial effect on structure and porosity and a negligible effect on texture. The range of soil texture and structure leads to difficulties in measuring with soils due to the inherent heterogeneity of samples and it is challenging to achieve repeatability between tests. Even within a small area of a field there can be multiple soil textures and structures. For this reason frequent measurements over small areas of soil are required to accurately estimate soil properties within a field.

The soil type influences the ability to hold water. As water enters the soil air begins to be displaced. Once all soil pores are filled with water the soil is saturated and said to be at its maximum retentive capacity. The fraction of air-filled pore space by volume must be approximately $10 \%$ for most roots to survive [Kirkham 2004]. After wetting of the soil to saturation, gravity will draw water downwards with larger pores being drained of water first, until it reaches field capacity. On further removal of water, for instance due to evapo-transpiration, the soil approaches the wilting point at which plants can no longer extract water from the soil as the binding forces are too great. As a guideline the saturation point of soils occurs at a gravimetric water content fraction of approximately $30-40 \%$ but is very dependent on soil type. The ability to measure the soil moisture level can assist in farming techniques such as dynamic irrigation, where water is only provided to crops as necessary. Moisture content is an important parameter that influences the electrical impedance of a soil. The water provides ionic 
pathways that lead to reduced electrical resistance. However, electrical impedance of soil is also influenced by other parameters such as soil structure, texture, compaction, temperature, organic matter and salinity. In order to estimate the water content from measurements of electrical impedance, it is necessary to understand the effects that such factors have on the electrical impedance.

Many geophysical mapping systems have been implemented and these have aimed to provide images of subsurface soil morphology, often with the desire to monitor soil water content. Typically, studies are performed either with ground penetrating radar (GPR) [Binley et al 2001], electrical resistivity measurements [Greve et al 2010, Chang Seop et al 1997, Binley et al 2001], or from surface probes [Herman 2001, Szarka 1987]. GPR is typically limited by soil moisture content and in very wet soils the measurement range is severely limited. Other technologies such as neutron probes are inhibited by cost and legislation.

Measurements in typical geophysics applications using surface-penetrating electrical currents are taken between pairs of electrodes placed at the soil surface. Individual impedance measurements of soil will provide only a bulk measurement of apparent resistivity between electrodes. A more complete 'view' of the soil is achieved through physical movement of the electrodes above the ground to change the region of soil being interrogated. Using Vertical Electrical Sounding (VES) the separation between current injection electrodes is changed to determine horizontal boundaries beneath the soil surface. Loke [2001], Barker [1981] and Dahlin [1996] describe 2D resistivity surveys in environmental applications. Using "profiling", electrodes are moved along the surface of the ground at fixed separation to create a map of the soil resistivity at a selected depth. Vertical transitions between soil types, rocks and air pockets can be imaged. Relatively little sub-surface imaging has been performed at the individual plant scale. A few examples, [Amin et al 1993, Hedberg et al 1993, Anderson et al 1992, Luo et al 2008], have monitored soil water movement and macropore configuration of undisturbed soil cores. These use either X-Ray or magnetic resonance imaging (MRI), which offer very high resolution, but are limited by size, equipment cost and agility in adapting to different conditions. Xray techniques can typically only be performed in the laboratory on shallow depth soil cores due to absorption. Using electrical resistance tomography (ERT) Binley et al [1996] inferred the preferential flow of water through an undisturbed soil column. In the present work identification of the distribution of water in the region of the plant roots is inferred directly from measurements of electrical impedance from a $2 \mathrm{D}$ array of electrodes.

Electrical impedance measurements of soil present some challenges. Excellent work has been done by Zimmermann et al [2008a, 2008b] using high resolution phase measurements to study the polarisation properties of soils and sediments. Typically, electrical measurements in soil require galvanic contact between electrodes and soil to enable current flow. With this arrangement electrode polarisation occurs due to a change between electron and ionic conduction at the soil-electrode interface. Other applications are subject to the same challenges, for instance in monitoring pressure filtration [York et al 2005]. In addition, contact with the soil can lead to corrosion of the electrodes. 
Therefore, the present work has explored the use of insulated electrodes which has the potential to reduce the influence of these effects. In the present work electrodes are insulated by use of a cured PCB solder laminate, chosen for its strength and high value of permittivity [Bungard, 2013]. Visual observation and repeatability of the measurements suggests that the insulating layer was stable for the period of the tests. Measurements have been conducted on small vessels, called "rhizotrons", which are typically used to enable visual observation of the root zones of plants. Preliminary results to introduce and verify the technique can be found in Newill et al [2013].

Section 2 discusses the use of insulated electrodes. This is followed by verification of the analytical model of the electrode structure through laboratory-based measurements performed with parallel-plate test cells. The effect of soil moisture, compaction and temperature are explored. Finally, preliminary results from electrical impedance measurements on growing maize plants are presented.

\section{CAPACITIVELY-COUPLED CONTACTLESS CONDUCTIVITY (C4D)}

\subsection{Analysis of Capacitively Coupled Contactless Conductivity}

C4D provides measurement of electrical conductivity through an insulating layer that is placed between the electrode and medium under test. Originally this was motivated in order to detect the conductivity of saline solution in very small capillary pipes in which it would be logistically very difficult to fit conventional electrodes. The earliest work utilizing C4D for electrophoresis was published by Gas et al [1980] who implemented a four-electrode design. In direct-contact conductivity measurements a four-electrode design reduces the influence of any polarization effects as the current injection and voltage measurements are performed on different pairs of electrodes. However, since there is no direct contact, only two electrodes are required for C4D. As an example, Fracassi da Silva and do Lago [1998] used an axial arrangement consisting of two tubular electrodes around a capillary and found that frequency had a substantial effect on sensitivity.

Previous work has reported the use of the C4D technique in an electrical tomography application [Wang et al 2012]. They implemented a simple electrical model, as seen in Figure 1, to represent the electrical system for electrodes connected around the periphery of an insulating pipe containing a conductive fluid. Capacitances $\mathrm{C}_{1}$ and $\mathrm{C}_{2}$ approximate the capacitance of the dielectric wall and the resistance $\mathrm{R}$ represents the conductive fluid passing through a pipe network. Reconstructed images show that they were able to identify the location of a plastic object in the pipe.

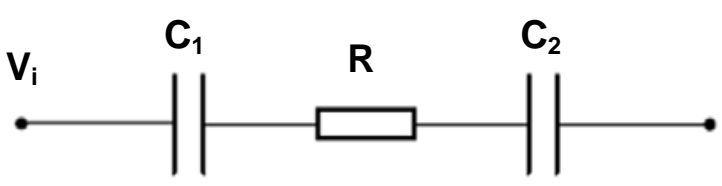

Figure 1: Wang C4D Model 
In the present work the Wang model is extended to include the resistive and reactive components of both the insulating layer covering the electrodes and the bulk material as shown in Figure 2. The resistive and capacitive components $R_{B}$ and $C_{B}$ depend on the bulk material. The impedance of the walls, $R_{W_{1}}, R_{W_{2}}, C_{W_{1}}, C_{W_{2}}$ do not change for the period of the measurements. As they are, essentially, identical they can be considered as a single, parallel connected, $R C$ impedance comprising $R_{W}$ and $\mathrm{C}_{\mathrm{W}}$. Since only the complete impedance of the system can be measured, the challenge is to extract the bulk impedance from the total impedance.
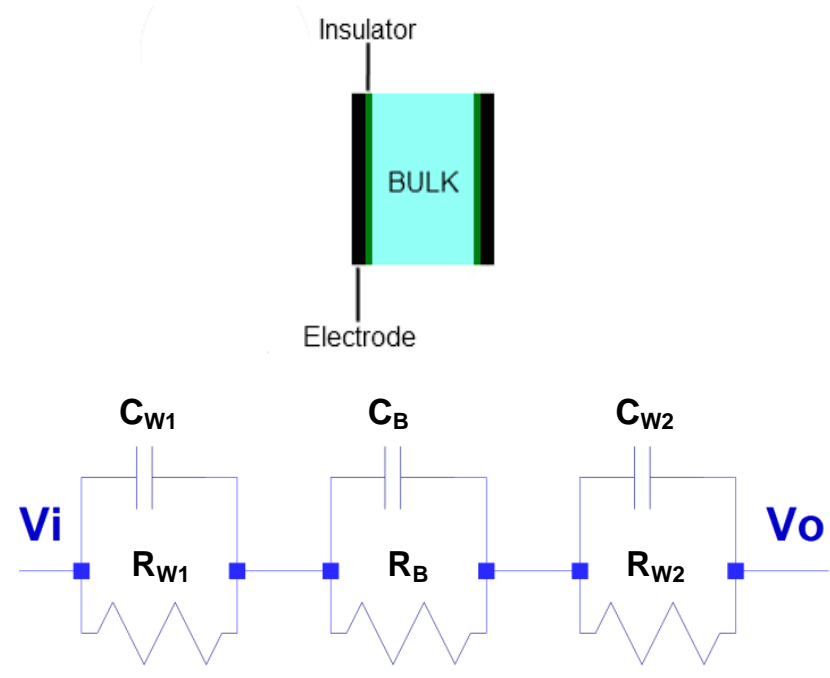

Figure 2: System Block Diagram and Electrical Model for the C4D Configuration.

By combining the two identical wall impedances into a single value of impedance, having resistive and capacitive components $R_{W}$ and $C_{W}$ respectively, the expression for the impedance of the combined wall and bulk material is:

$Z_{T}=Z_{W}+Z_{B}=\left(\frac{R_{W} X_{W}^{2}}{R_{W}^{2}+X_{W}^{2}}+\frac{R_{B} X_{B}^{2}}{R_{B}^{2}+X_{B}^{2}}\right)-j\left(\frac{R_{W}^{2} X_{W}}{R_{W}^{2}+X_{W}^{2}}+\frac{R_{B}^{2} X_{B}}{R_{B}^{2}+X_{B}^{2}}\right)$

$Z_{T}$ is the total complex impedance comprising the wall and bulk impedances with the associated resistive and reactive components. It is instructive to consider the real and imaginary components of the complex impedance $\left(Z_{W}\right.$ and $\left.Z_{B}\right)$. These have contributions from both resistive and reactive parts of the wall and bulk materials $\left(R_{W}, R_{B}, X_{W}, X_{B}\right)$ and the behaviour may not be immediately obvious. Figure 3 shows the frequency dependence of the real and imaginary components of the complex impedance. Values have been calculated using the analytical model represented by Equation 1 assuming that tap water is the bulk material contained in a parallel-plate test cell. The aim is to understand the behaviour of the real component of the impedance. At low frequencies, below about $100 \mathrm{~Hz}$ the real component of impedance is, essentially, independent of frequency and approximates to the resistance of the insulating layer. Also in this region the imaginary component gradually increases until, at about $1 \mathrm{kHz}$ the two are equal. Above $1 \mathrm{kHz}$ both components decrease, the real 
component at a faster rate than the imaginary, until it reaches a plateau region extending from $30 \mathrm{kHz}$ to $700 \mathrm{kHz}$. Crucially, for this technique, it is within this region that the impedance is representative of the bulk material properties. The final decrease in real impedance is dictated by the permittivity of the bulk material.

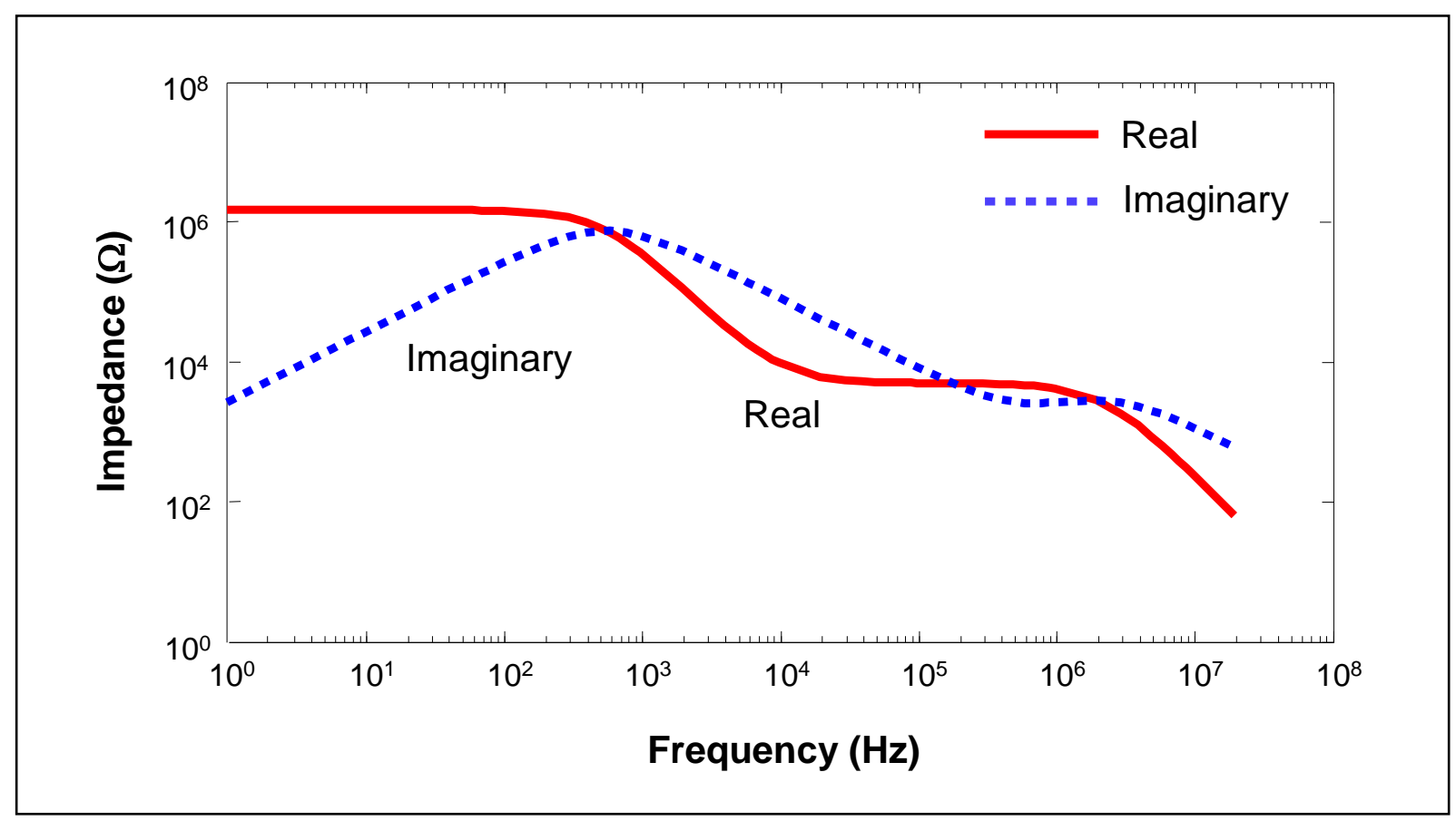

Figure 3: Simulated Complex Impedance using Tap Water as the Bulk Material.

\section{EXPERIMENTAL SETUP}

\subsection{Parallel-Plate Test Cell}

The C4D analytical solution described above has been verified with measurements on parallel-plate test cells. These were constructed from $3 \mathrm{~mm}$ thick Perspex with insulated electrodes, each measuring $3 \mathrm{~cm} \times 3 \mathrm{~cm}$, placed on opposite sides. Capacitively-coupled measurements were acquired at excitation frequencies from $10 \mathrm{~Hz}$ to $13 \mathrm{MHz}$. using a Hewlett Packard 4192A impedance analyser. Consideration of the spectroscopic response for water identified the plateau region representing the real component of impedance for the bulk material. In addition the test cells have been used to explore the effect of moisture, compaction and temperature on impedance measurements of soil. An environmental chamber was used to control the temperature which was varied from $5^{\circ} \mathrm{C}$ to $40^{\circ} \mathrm{C}$ in $5^{\circ} \mathrm{C}$ steps. Four levels of uniform compaction, numbered 1-4 and corresponding to pressures of 0.05 $\mathrm{kg} / \mathrm{cm}^{2}, 0.11 \mathrm{~kg} / \mathrm{cm}^{2}, 0.16 \mathrm{~kg} / \mathrm{cm}^{2}$ and $0.21 \mathrm{~kg} / \mathrm{cm}^{2}$ as measured using a Geotest E-280 Pocket Penetrometer were considered. 


\subsection{Rhizotron}

A rhizotron provides a method for non-invasive viewing of the region around the roots of plants. Typically it has at least one transparent panel. The rhizotron might be constructed for use in a laboratory or could be built underground [James et al 1984, Busch et al 2006, Taylor 1991]. Dimensions can range from centimetres to several metres. Rhizotrons allow the user to determine the properties of the soil and roots, typically through visual observations. This may include photographs, possibly with image processing, to determine the colour contrast between wet and dry soil, or to identify roots. Regardless of the measurement technique, the use of visual observations is compromised as features can only be observed through a clear viewing window, accompanied by reflections, and these do not extend to within the bulk of the soil core.

The present work employs laboratory-scale rhizotrons measuring $0.4 \mathrm{~m} \times 0.6 \mathrm{~m} \times 0.05 \mathrm{~m}$. One side of each rhizotron has the traditional transparent viewing panel. On the opposite side is a $10 \times 6$ array of capacitively-coupled electrodes as shown in Figure 4. These are used to provide measurements of electrical impedance in the soil during the growth cycle of maize plants. The evolution of the distribution of water content is inferred directly from measurements between adjacent electrodes. While allowing plants to grow with relative freedom the root system is confined within what is essentially a 2D space. Electrodes are selected and activated using the measurement system described below.

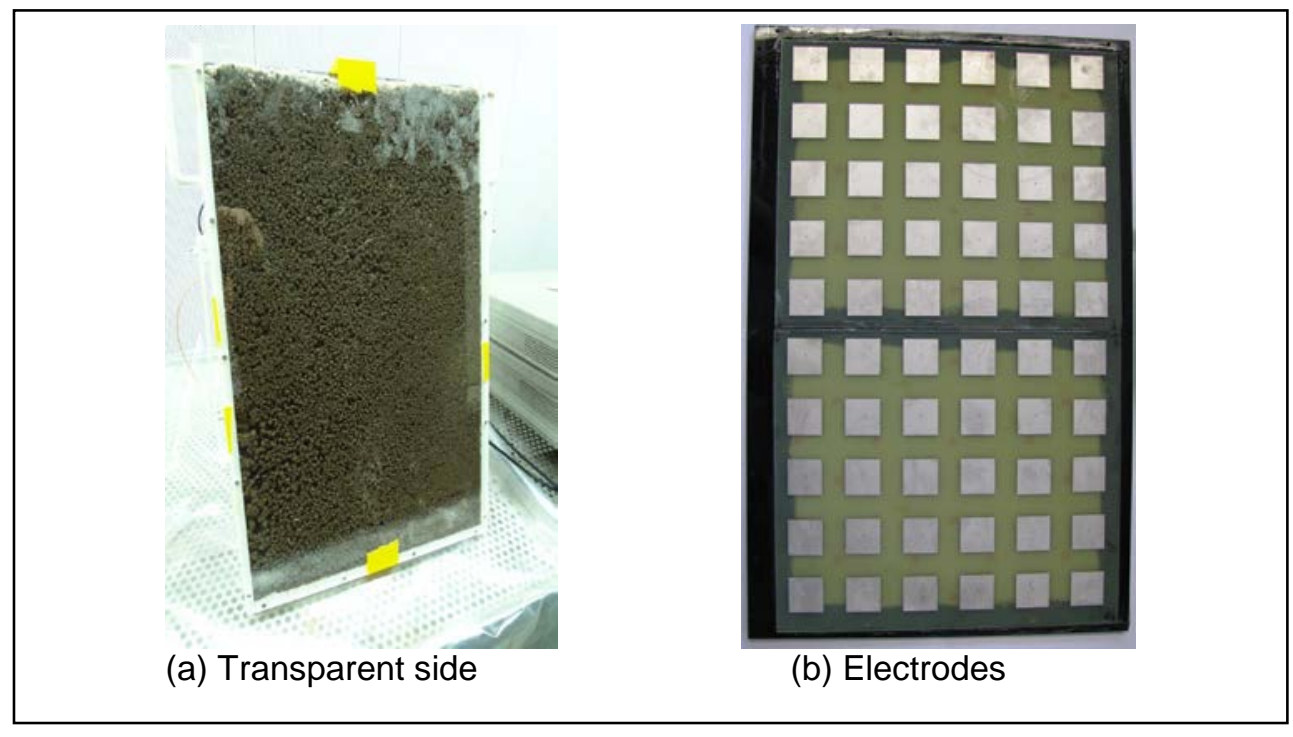

Figure 4: Photographs of the rhizotron

\subsection{Measurement System}

An array of 60 electrodes, configured as 10 rows and 6 columns, with accompanying bespoke switching electronics, is attached to the back plane of each rhizotron. Each electrode is separated from the soil by the thin insulating layer. An impedance analyser and desktop PC are the only other pieces of equipment. One impedance analyser can be switched between several rhizotrons. Figure 5 
shows the system block diagram and how the 6 main components are interfaced. The desktop PC, hosting bespoke software "TabUMS", supervises a user defined switching pattern of the electrodes. Parallel rhizotrons can be interrogated using the switching network.

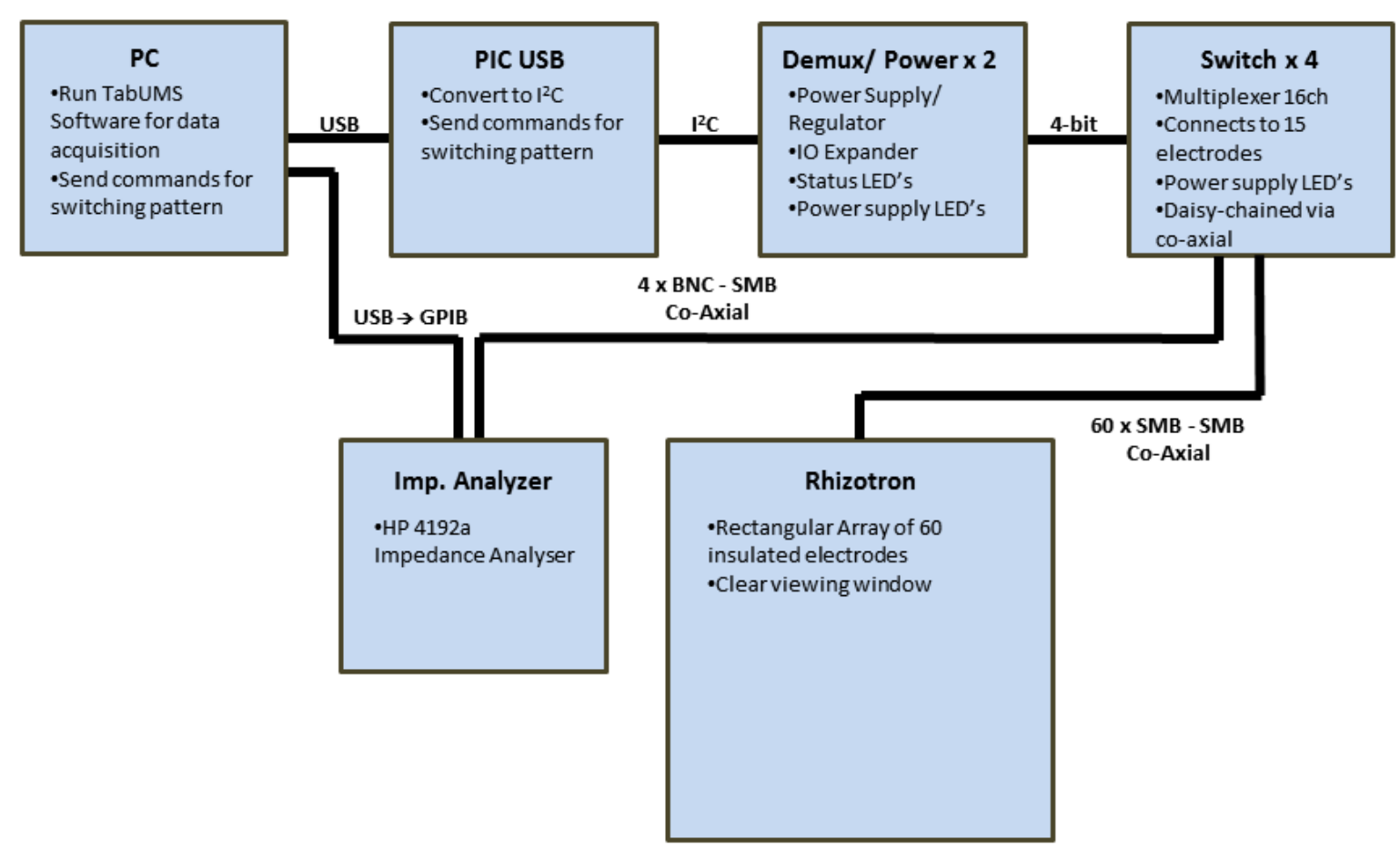

Figure 5: Measurement System Block Diagram

Each electrode is connected to one output of a 16 channel Analog Devices ADG1206 multiplexer on the "Switch" PCB. Four multiplexers are required for the 60 electrodes. Switching is required to 'activate' selected pairs of adjacent measurement electrodes. The 4-bit address lines of the ADG1206 multiplexers are controlled by the power/ demux PCB. The board features a PCF8574 8-bit IO expander which communicates with the PIC32 via I2C. One 10 expander can only control two multiplexers and therefore two demux PCBs are required for each rhizotron. The 8-bit operation of the 10 expander is separated into two channels. Four bits are used to control switch PCB 1 while the remainder control switch PCB 2. The expander control commands are provided by a configuration file on the desktop computer. The demux PCBs also provide the power to operate the multiplexer ICs. A Texas instruments TPS61041 Switch Boost Converter creates $\pm 15 \mathrm{~V}$ rails for the ADG1206. At higher frequencies the measurements become increasingly susceptible to parasitic effects. In order to reduce the effect shielded coaxial cables are used wherever possible. In addition, all cables were clearly labelled to reduce variations between tests.

For each cycle a command is propagated through the system from the PC to the switch PCB's to activate the required pairs of electrodes. Once activated, the PC sends a command to the impedance analyser via the Prologix USB-GPIB interface to measure the complex impedance. This is repeated for every electrode pairing. Bespoke software on the PC supervises serial communication with the 
switching electronics. The software can be configured to acquire a selected number of measurements, or run indefinitely at user defined time intervals. The measured impedances are stored in ".csv" file format. Impedance measurement data are processed in MATLAB to yield a plot of impedance over time at all adjacent electrode pairings in a video format.

The rhizotron measurement system creates an image of soil moisture distribution by measuring the real and imaginary components of impedance between pairs of adjacent electrodes placed along the back plane of the vessel. Measurements are taken between all horizontally and vertically adjacent electrodes except, for technical reasons, the rightmost column, resulting in 95 measurements per frame. Sequential frames are taken over time and combined to create a movie providing a temporal representation of soil moisture distribution as viewed from the side of the rhizotron.

\subsection{Preliminary Exploration of Plant Growth}

After the analytical solution was verified with parallel-plate measurement data, focus was turned to the acquisition of growth data using the rhizotron test vessels. Plant growth tests were performed to determine whether the technique is capable of measuring changes in soil moisture content. Three rhizotrons were interrogated in parallel. One rhizotron acted as a control, with no plant, and each of the remaining two vessels hosted a maize plant. Maize was chosen due to its rapid growth characteristics which lead to significant uptake of moisture. Growth chambers were used to mimic a diurnal cycle comprising 18 hours of daylight at $25^{\circ} \mathrm{C}$, and 6 hours of darkness at $10^{\circ} \mathrm{C}$. Following the rhizotron growth tests, results were analysed to determine the temporal and spatial movement of moisture through the soil.

\section{RESULTS AND DISCUSSION}

\subsection{Measurements to Explore the Performance of C4D System}

The aim of the tests described in this section was to determine how accurately the electrical properties, specifically the real impedance, of the bulk material can be estimated using capacitively coupled measurements. Initial tests considered water as the bulk material to allow laboratory bench conductivity meters to verify impedance measurements The electrical conductivity of the water was measured using a commercial probe and, from knowledge of the geometry of the cell, converted to resistance and assigned to the variable " $\mathrm{R}_{\mathrm{B}}$ " in the analytical solution. As previously mentioned, above $1 \mathrm{MHz}$ the relative permittivity of the bulk material dictates the decrease in real impedance seen in Figure 6. Small changes in the value of the relative permittivity of water have no measurable effect on the impedance at the selected plateau frequency for water. Therefore, a fixed value of 80 was used for the relative permittivity of water. The parameter is referred to as $C_{B}$ in the model shown in Figure 2 . For soil based measurements the range of values for the relative permittivity is large compared to water, from as little as 3-4 for dry soil, to 50 for saturated soil [Smith 1993]. As relative permittivity of the soil sample increases, the 'roll-off' will occur at lower frequencies. This will reduce the bandwidth of 
the plateau region, making selection of the plateau frequency more difficult. An advantage of the large range of relative permittivity values experienced in soil is that the changing roll-off frequency may be useful in estimating the capacitance of the soil, which may help improve estimations of moisture content. This is to be explored in future work.

Figure 6 suggests good agreement between the measured impedance and simulated values. The most significant differences lie between frequencies of $10 \mathrm{~Hz}$ and $1 \mathrm{kHz}$, at the "knee" of the curves. These differences in values are attributed to the use of fixed values of relative permittivity in the simple electrical model that has been proposed for the insulated electrode measurement system. It is known that the relative permittivity of water changes with frequency. It is also expected that the relative permittivity of the insulating layer will change with frequency. However, in the present model it is assumed that the impedance and permittivity of each component is not frequency dependent. This may lead to inaccuracies in calculated impedance compared to measured data. The differences at low frequency are not crucial to the present work as this lies outside the "plateau" region of interest. Between frequencies of $50 \mathrm{kHz}$ and $10 \mathrm{MHz}$ the average difference between the theoretical and measured impedance fraction is $5 \%$ with a maximum of $12 \%$. Within the plateau region, between frequencies of $30 \mathrm{kHz}$ and $100 \mathrm{kHz}$, the average error in impedance fraction is $3 \%$ with a maximum of only $4 \%$. Similar consistency was observed between measurements and simulations using de-ionised water.

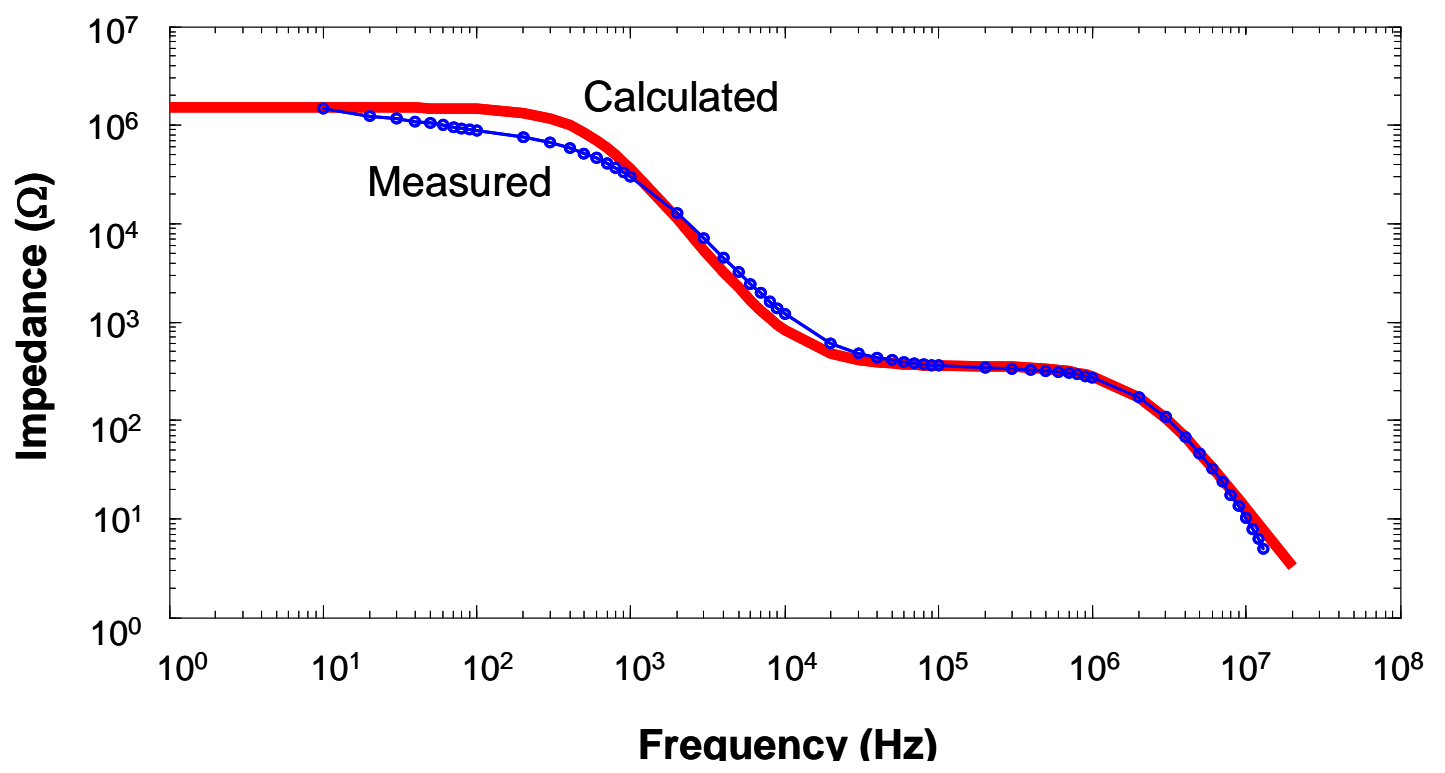

Figure 6: Comparison of Calculated and Measured Impedance for Tap Water

\subsection{Measurements on Soil}

Following verification of the model using water as the bulk material soil-based measurements were performed. The soil comprises gravimetric fractions of $61 \%$ sand, $20 \%$ silt and $19 \%$ clay and, according to the USDA textural class, is therefore identified as a sandy loam. The aim of these measurements was to explore the effect of variations in moisture, compaction and temperature on the 
measured electrical impedance to determine how significant the influence of temperature and compaction was on the impedance of the soil compared to changes in moisture level. Topp et al [1980] considered the effects on the dielectric properties of soils within the $\mathrm{MHz}$ to $\mathrm{GHz}$ range of frequencies. They found that the largest variation in the soil properties arose from texture, structure, soluble salts, water content, temperature and measurement frequency. In this work the effect of soluble salts was not considered further but by using soil from the same batch variation between tests is reduced.

Figure 7 shows the variation of impedance due to changes in soil moisture and compaction. The changes due to compaction are relatively small but in all cases the impedance is reduced as compaction is increased. As expected the measured electrical impedance becomes less resistive as moisture content increases. As soil moisture decreases from a gravimetric fraction of $30 \%$ to $15 \%$ the relatively low value of impedance changes by a factor of about 10 , from $1 \mathrm{k} \Omega$ to $10 \mathrm{k} \Omega$. This change becomes more pronounced as the moisture level decreases further, changing by a factor of 100 , from $10 \mathrm{k} \Omega$ to $1 \mathrm{M} \Omega$, as the moisture drops from a gravimetric fraction of $15 \%$ to $5 \%$. The influence of compaction on measured impedance is more significant, compared to soil moisture, for dry soils. At a gravimetric fraction of $5 \%$ moisture the impedance decreases from $1.4 \mathrm{M} \Omega$ to $800 \mathrm{k} \Omega$ as the soil compaction is increased from level 1 to 4 . The same change would be produced by an approximate increase in soil moisture from a gravimetric fraction of $5 \%$ to one of $6 \%$. Considering wet soil, with a gravimetric fraction of $25 \%$ moisture, the same change in compaction changes the impedance by only $1.4 \mathrm{k} \Omega$ to $1.1 \mathrm{k} \Omega$. This change would be produced by an increase in moisture from a gravimetric fraction of $25 \%$ to $28 \%$. Consequently, under wet conditions, the effect of compaction on electrical impedance is more significant and it becomes difficult to separate the influence of moisture and compaction. As soil compaction is unlikely to change dramatically during a growth period then any change of impedance might typically be attributable to change in moisture.

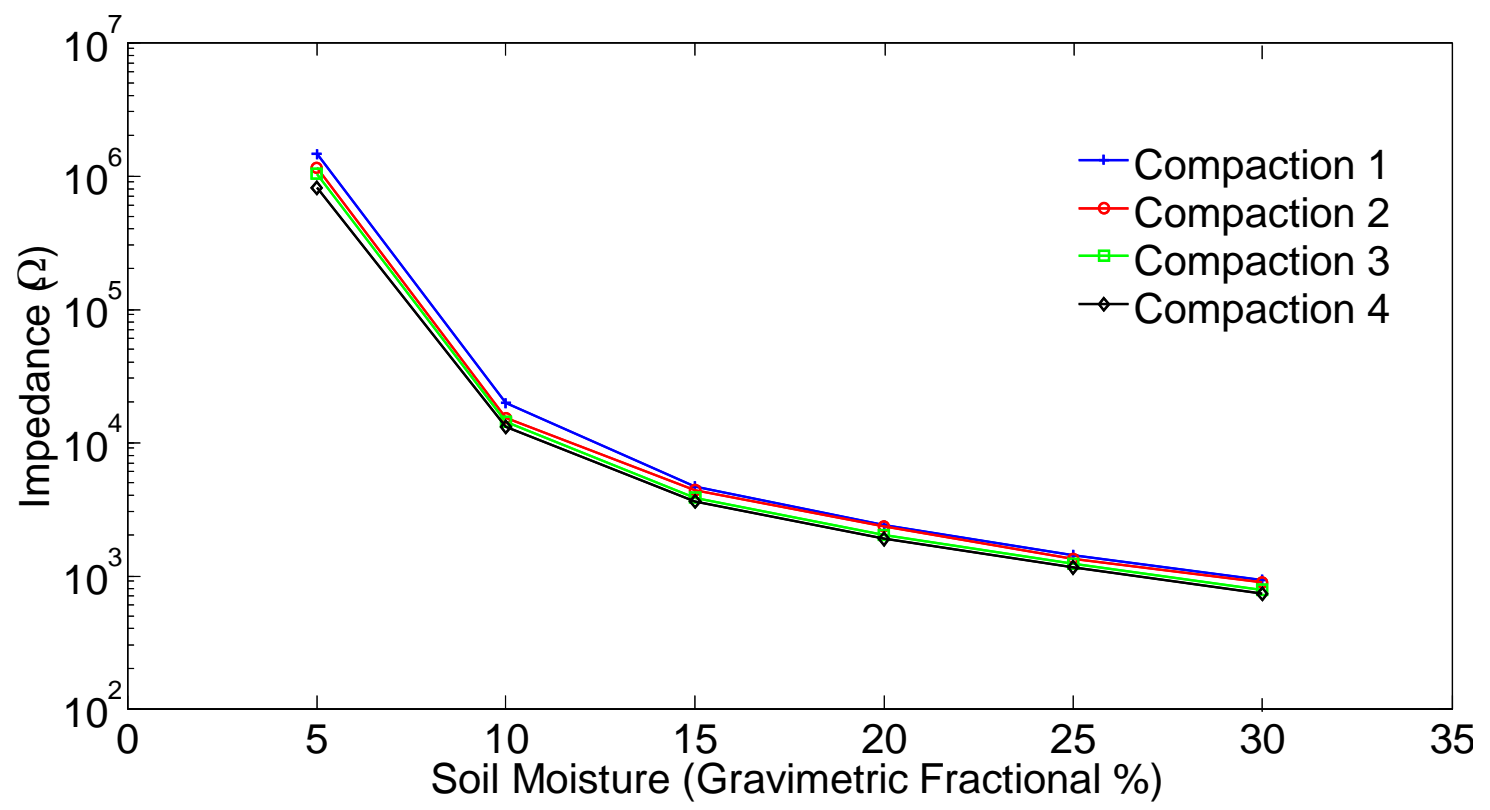

Figure 7: Effect of Soil Moisture and Compaction on Measured Electrical Impedance. 
Figure 8 is similar to Figure 7. In this case it provides a comparison of changes to electrical impedance due to variation of both soil moisture and temperature. The measured impedance is consistently higher at lower temperature. As with compaction testing, in drier soils the effects of temperature variation on electrical impedance are significantly smaller than those caused by changes in soil moisture. As soil moisture content increases the effects become more difficult to differentiate, with the variation due to temperature in high moisture content soils becoming more significant compared to variations due to moisture. However, unlike the case for compaction, a simple linear approximation exists from which the electrical impedance can be correlated to temperature. Analysis of test data showed that a temperature fraction change of $2 \% /{ }^{\circ} \mathrm{C}$ provided a suitable linear approximation for correction. Not surprisingly this value is similar to that experienced in water.

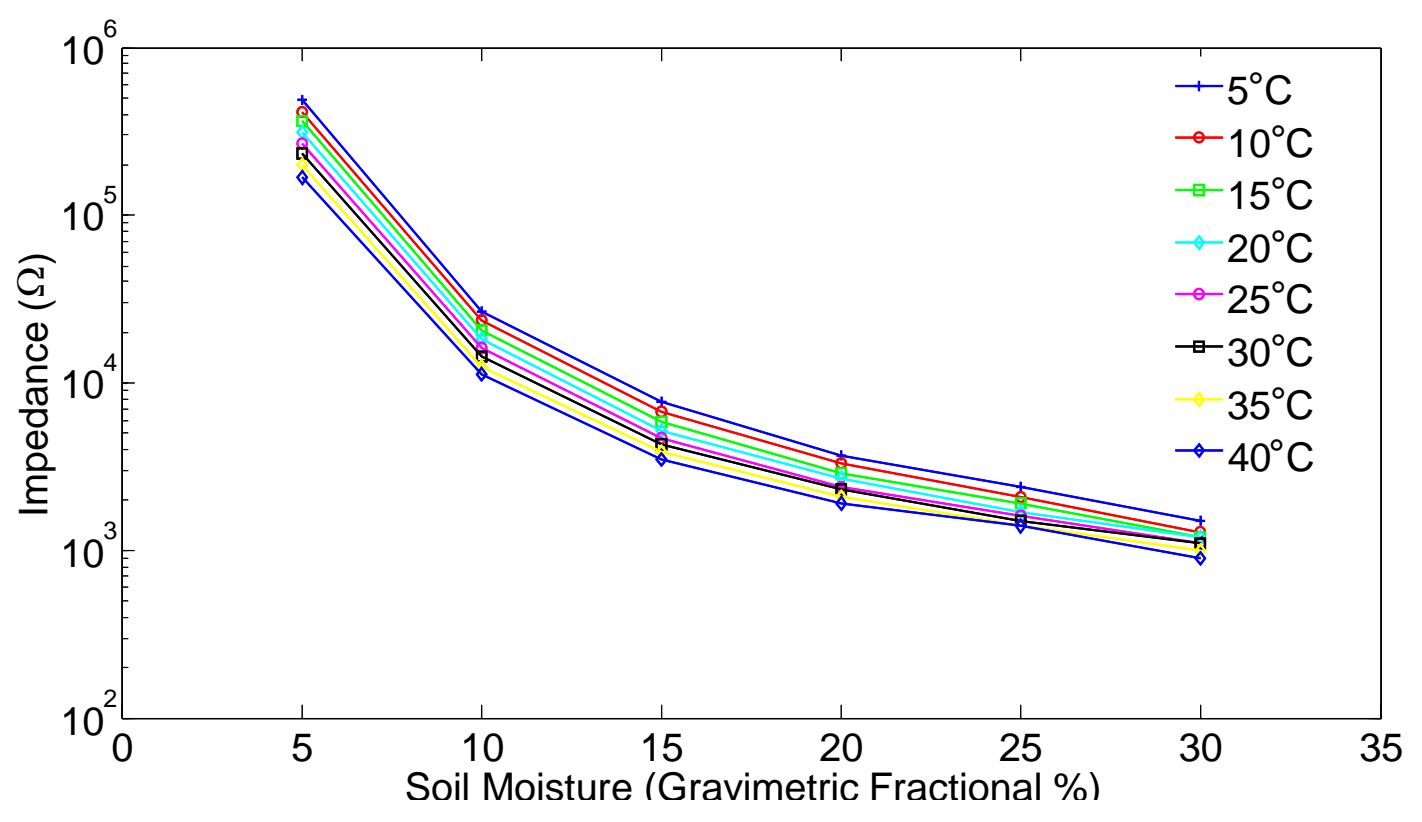

Figure 8: Effect of Soil Moisture and Temperature on Measured Electrical Impedance.

In conclusion, C4D measurements are shown to be capable of providing changes in electrical impedance that reflect the influence of water, compaction and temperature. Linear approximations of soil impedance can provide correction for temperature. While no such approximation was available for soil compaction, the change of soil bulk density due to compaction is limited compared to the changes due to water content and temperature, which will fluctuate daily.

\subsection{Water Distribution During Plant Growth}

Following characterisation of the measurement technique, using parallel plate test cells containing water and soil, trials were conducted on rhizotrons housing maize plants grown from seed. The aim of the trials was to explore the potential for the technique to be used to determine the distribution of water around the roots of growing plants from measurements of electrical impedance. Two trials were conducted each lasting several weeks. Each trial considered three rhizotrons, two containing growing maize plants and one as a control containing only soil. A different rhizotron was selected as the control 
for the two trials in order to eliminate the chance of preferential behaviour in a particular vessel or position in the growth chamber. The rhizotrons were sealed at the top to reduce leakage of moisture through evaporation and weed growth. A hole was left in the covering layer in each rhizotron to allow the plant to grow. This was mimicked in the control vessel for consistency. The two trials are identified as "T1" and "T2" and the three rhizotrons as "FNS1", "FNS2" and "FNS3". Therefore "T1-FNS1" refers to rhizotron 1 in trial 1 . The three rhizotrons were connected in parallel to the measuring system and interrogated sequentially. Measurements were made between each horizontally and vertically adjacent pair of electrodes. For the trials each rhizotron was filled with sieved soil. This was wetted to saturation and left to drain for a period of approximately 24 hours to reach field capacity which was estimated to be a gravimetric fraction between $30 \%$ and $35 \%$ water content. Each rhizotron was interrogated at frequencies of $10 \mathrm{kHz}, 50 \mathrm{kHz}, 100 \mathrm{kHz}, 500 \mathrm{kHz}$ and $1 \mathrm{MHz}$ and the complete frame of measurements for each rhizotron took about 5 minutes to acquire. Measurements were repeated every hour.

Results from the two trials were similar, with some differences in growth being evident due to the inherent non-uniformities in the growing conditions. Results from trial 2 are presented here and are representative of both trials. Photographs of the three rhizotrons after 9 weeks growth at the completion of trial 2 are shown in Figure 9. The trials were terminated when the plants began to show signs of stress as water availability reduced as evidenced by discoloration of the leaves and wilting. Clearly, as expected, there is no evidence of significant growth in the control vessel FNS3. The plants in FNS4 and FNS5 achieved heights of $79 \mathrm{~cm}$ and $71 \mathrm{~cm}$ respectively.

The plants were carefully removed from the soil for post trial analysis and are shown in Figure 10 While some root mass was lost due to the fragility of roots, the majority was preserved. A weed that grew in FNS5 is also shown for comparison. The aim of this test was to observe whether the complete plant mass correlates with the remaining moisture content of the soil. Accurate measurement of the height of the plant is, naturally, challenging but both the height and the mass differ by fractional heights of $9 \%$ for the plants from FNS4 and FNS5.

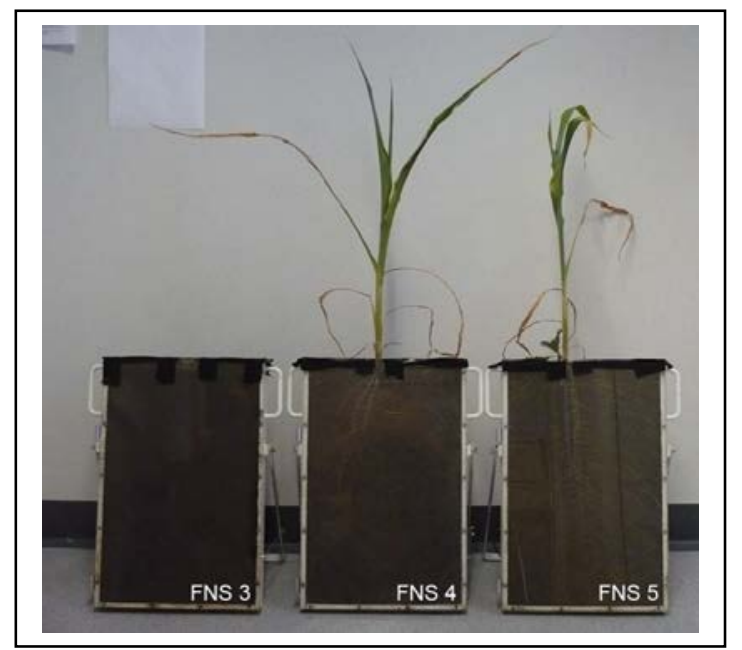

Figure 9: Growth of the maize at the completion of trial 2 


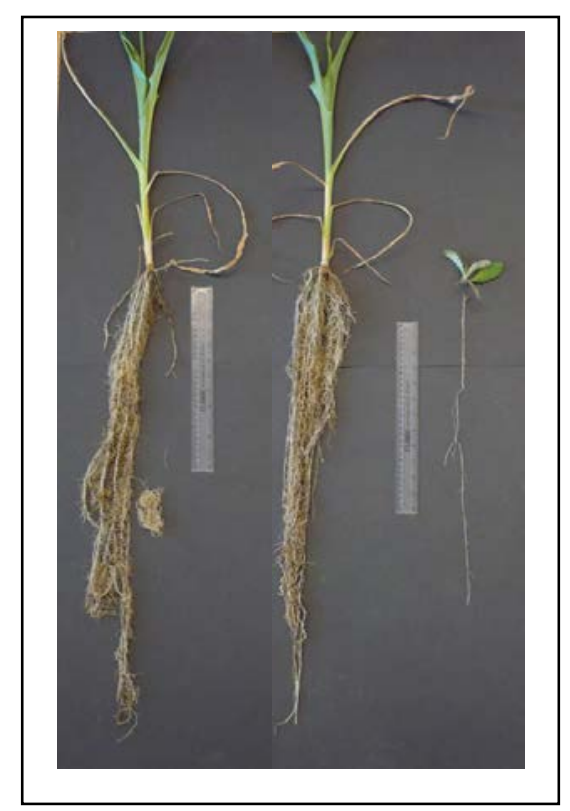

Figure 10: Post-Trial Root Bundles for T2-FNS4 and T2-FNS5

All growth vessels showed significant cracking in the soil. It should be noted that such cracking compromises the measurement of electrical impedance due to the discontinuities that arise. As can be seen in Figure 11, the cracking in T2-FNS5 is greater than in T2-FNS4 despite the fact that the resulting maize plant is smaller. At the completion of the trial three small soil samples were removed from each rhizotron vessel in order to determine the gravimetric soil moisture content through weighing, drying and re-weighing the soil samples. The samples were removed from the same position in each rhizotron, corresponding to bottom, middle and top locations. Results are shown in Table 1. Clearly the control vessel (T2-FNS3) shows greater water content and this increases with depth in the rhizotron. This might be expected due to the inevitable loss through evaporation. Results from the growth vessels in Trial 2 reveal similar amounts of water from which it is not possible to deduce anything regarding variation with depth or size of plant. It is worth noting that for Trial 1 , in which one plant showed a fractional height about 50\% larger than the rhizotron housing the smaller plant, a significantly greater water content was observed at the conclusion of the trial.

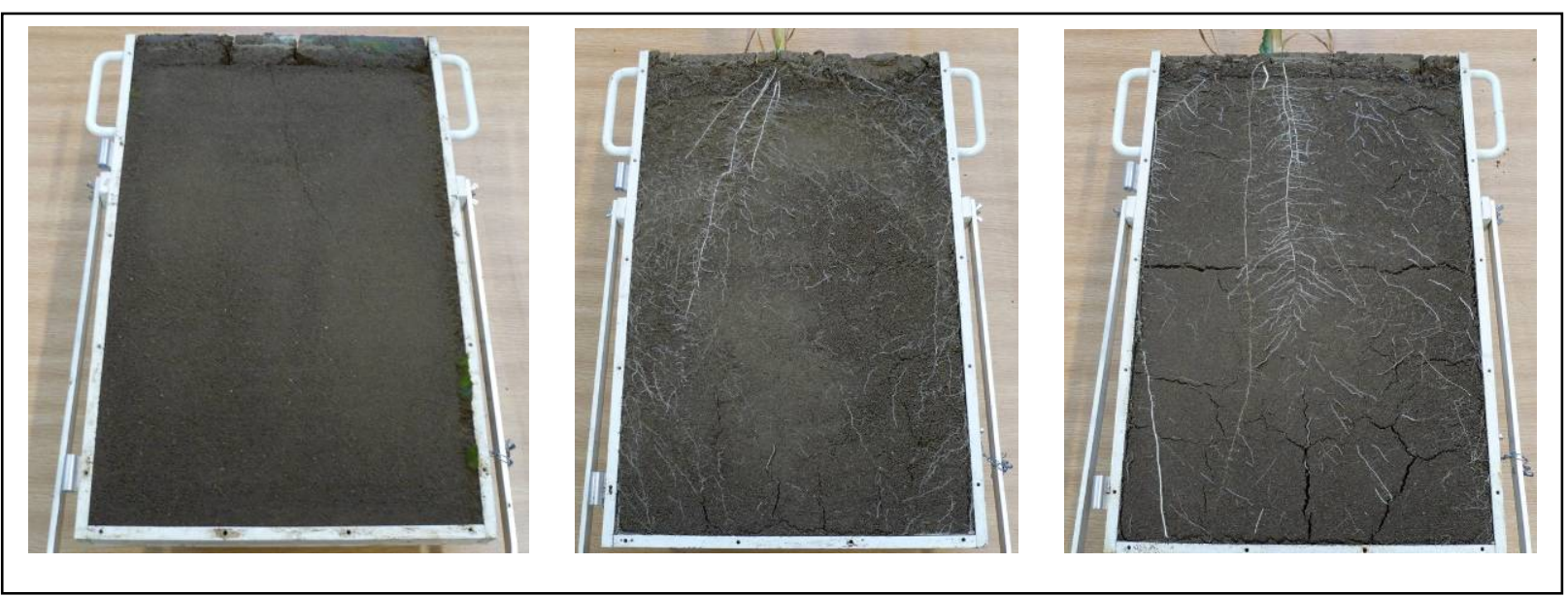

Figure 11: Post-trial photographs of soil cores from T2-FNS3, T2-FNS4 and T2-FNS5. 


\begin{tabular}{c|ccc}
\multirow{2}{*}{ Soil Sample Location } & \multicolumn{3}{|c}{ Gravimetric Fraction (\%) } \\
& T2-FNS3 & T2-FNS4 & T2-FNS5 \\
\hline Top & 9.0 & 4.3 & 4.0 \\
Middle & 11.5 & 3.6 & 4.5 \\
Bottom & 12.4 & 4.0 & 3.6
\end{tabular}

Table 1: Post-test gravimetric soil moisture content for rhizotron growth trial 2

As discussed above the electrical impedance measurements in the parallel plate test cell revealed a temperature fraction change of about $2 \% /{ }^{\circ} \mathrm{C}$. Figure 12 shows the measured impedance for a pair of electrodes in the control vessel over a period corresponding to 15 diurnal cycles each ranging from 10 ${ }^{\circ} \mathrm{C}$ to $25^{\circ} \mathrm{C}$. From a minimum of $3500 \Omega$ a maximum of $4550 \Omega$ might be anticipated for an increase of $15{ }^{\circ} \mathrm{C}$. Figure 12 shows a maximum of approximately $4500 \Omega$, corresponding to a temperature fraction change of $1.9 \% /{ }^{\circ} \mathrm{C}$ which is in good agreement with expectations.

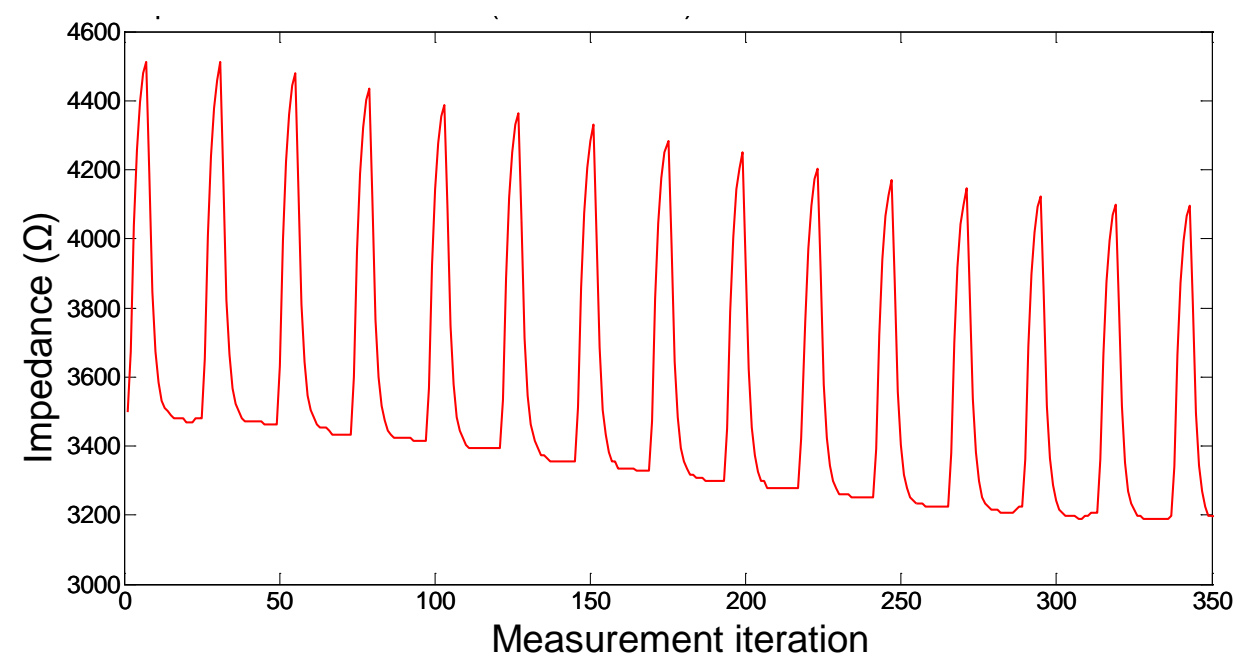

Figure 12: Measured impedance for 15 diurnal cycles in the control vessel

A similar analysis was undertaken on a growth vessel and results are shown in Figure 13. As can be seen the baseline impedance increases over time as the plant grows and water is extracted from the soil. Significant drying of the soil due to root water extraction can be seen to begin at approximately measurement 500, which correlates to day 20 . The soil then continues to dry throughout the test, which leads to a steady increase in the baseline of the impedance over the duration. During the early stages of growth, indicated by point "A", the diurnal measurements range from approximately $3400 \Omega$ to $4400 \Omega$ corresponding to a temperature fraction change of about $2 \% /{ }^{\circ} \mathrm{C}$. However at later stages of the growth period, when the amount of water in the soil is decreasing due to evapo-transpiration, the diurnal range suggests increases to a maximum temperature fraction change of approximately $5 \% /{ }^{\circ} \mathrm{C}$ at point "B" reducing to a temperature fraction change of $3 \% /{ }^{\circ} \mathrm{C}$ at point " $\mathrm{C}$ ". Clearly these values vary from the expected temperature fraction change of $2 \% /{ }^{\circ} \mathrm{C}$. It can be seen that this difference 
corresponds to the period when the change of impedance each day is largest, suggestive of maximum growth rate. Clearly this will affect the measurements relating to temperature change as the amount of soil moisture has changed between the "high" and "low" temperature measurements. For the present work reported below, measurements are taken at a fixed point in the simulated "diurnal" cycle, corresponding to a selected temperature. For future work, in less controlled environments, it will be necessary to further understand and accommodate temperature effects.

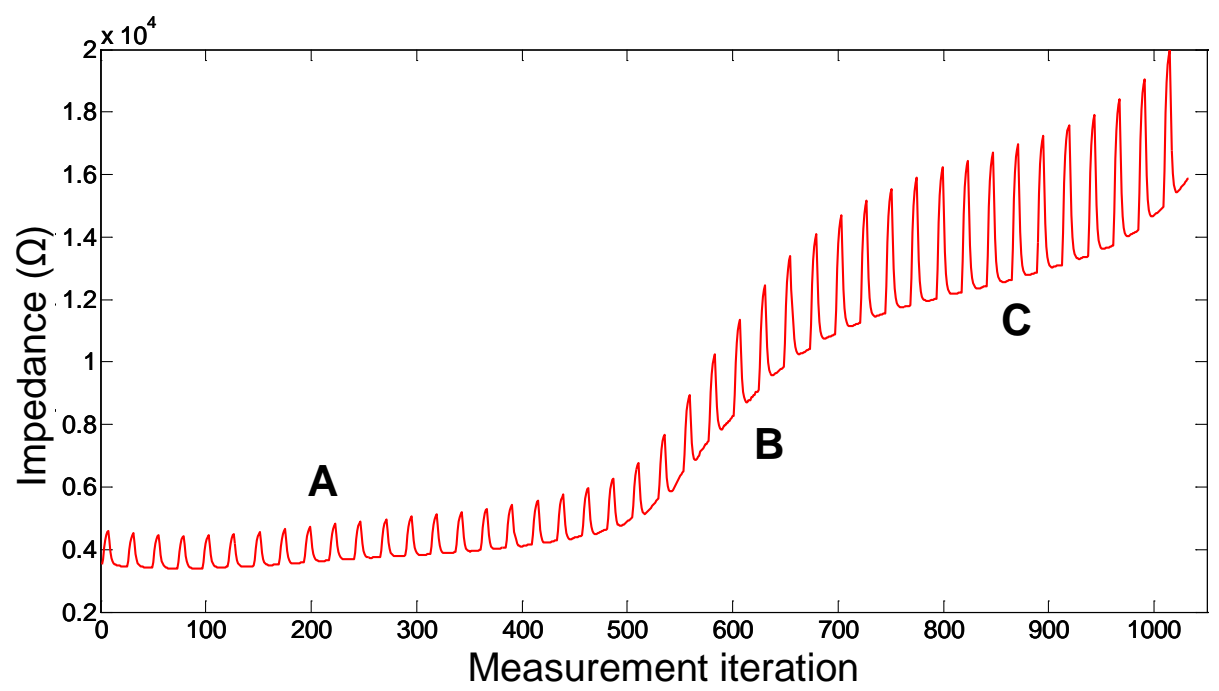

Figure 13: Measured impedance over the growing period in a growth vessel

Figure 14 shows screenshots of the movie files that were created from the resulting images for all three rhizotrons over the duration of Trial 2, at 15 day intervals. Acquired test data were interpolated to produce a smoother transition between adjacent electrode pairings. Measurements were taken at 1 $\mathrm{MHz}$ injection frequency, This frequency was chosen following preliminary test results in parallel-plate test cells which suggested that at low $\mathrm{MHz}$ frequencies the total measured impedance was least sensitive to the insulating layer. In order to mitigate against the effect of temperature when considering the change in impedance due to plant growth, measurements are used that correspond to a selected temperature. Blue represents low impedance at the start, when the soil is relatively wet, through to red representing high impedance at the end of the trial when the soil is dry. As can be seen all three rhizotrons display low impedance at the start when the soil is wet. In the second half of the trial the rhizotrons containing maize plants show gradually increasing impedance, with most change towards the top of the vessel. The range of the impedance measurements presents some difficulties for these colour-coded images as small changes are masked. A zoomed image of the control (FNS3) after 60 days shown in Figure 15, using the highest impedance that is measured in that vessel for calibration, more clearly reveals the smaller changes in impedance that occur. Clearly there is a progression from high impedance (red), dry soil, in a band at the top and likely to be due to evaporation, through to low impedance (blue), wet soil, that has not changed significantly, at the bottom. 


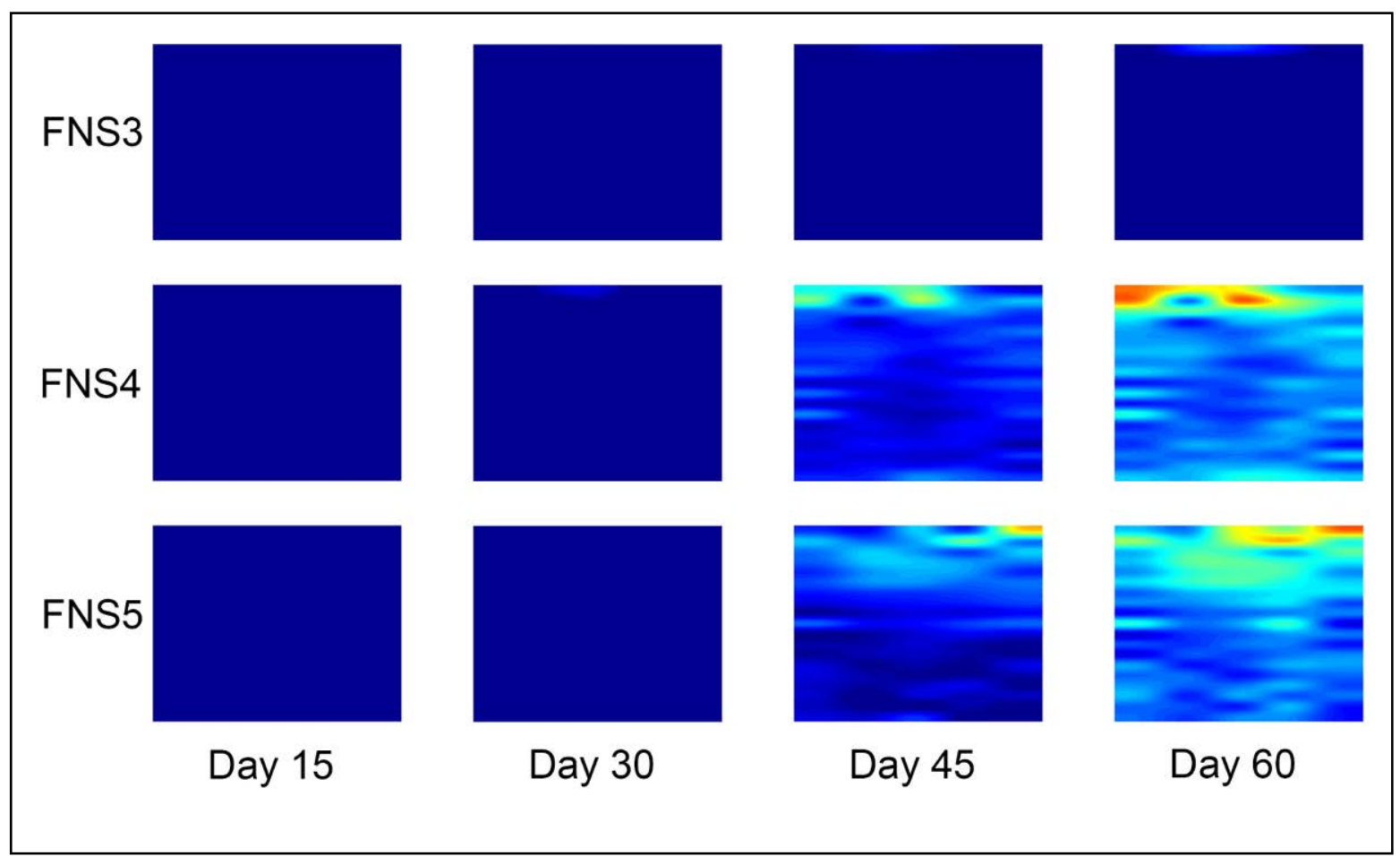

Figure 14: Screenshots of the movie representation of Trial 2.

Blue (dark) represents low impedance through red (light) representing high impedance. Each image represents a side view of the rhizotron

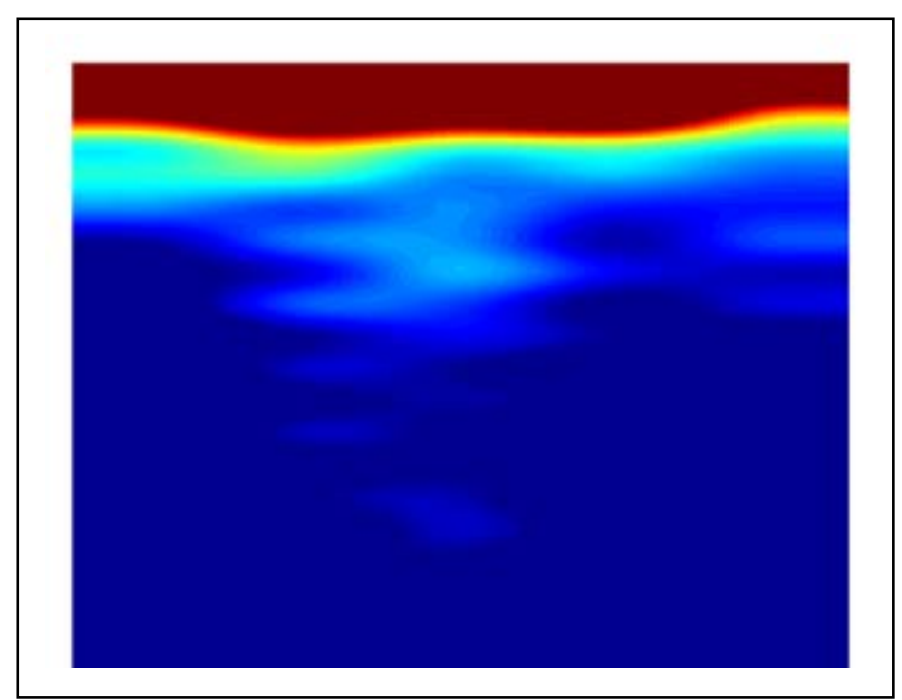

Figure 15: Zoomed image of the control vessel (FNS3) after 60 days Blue (dark) represents low impedance through red (light) representing high impedance.

The image represents a side view of the rhizotron

Figure 16 show graphs of the measured impedance for selected electrode pairs for FNS3, 4 and5. Each plot is positioned to represent the location of the measurement pair in the rhizotron. The "red" line in each graph represents the control rhizotron FNS3, where measurements are, essentially, constant. At the top there is evidence of increasing impedance, assumed to be due to evaporation. The "green" and "blue" lines represent the growth rhizotrons, FNS4 and FNS5 and clearly show increased change of impedance. 
Results suggest increased rates of change of impedance from about day 25 onwards. It is tempting to suggest that this onset is due to the increasing root mass but, of course, the same behaviour is apparent in the control vessel, for instance measurement 93, and therefore there is a strong influence due to evaporation. Comparison between measurements at the top and bottom, for instance 93 and 13 , suggest that the change in impedance ensues earlier towards the top of the vessel.

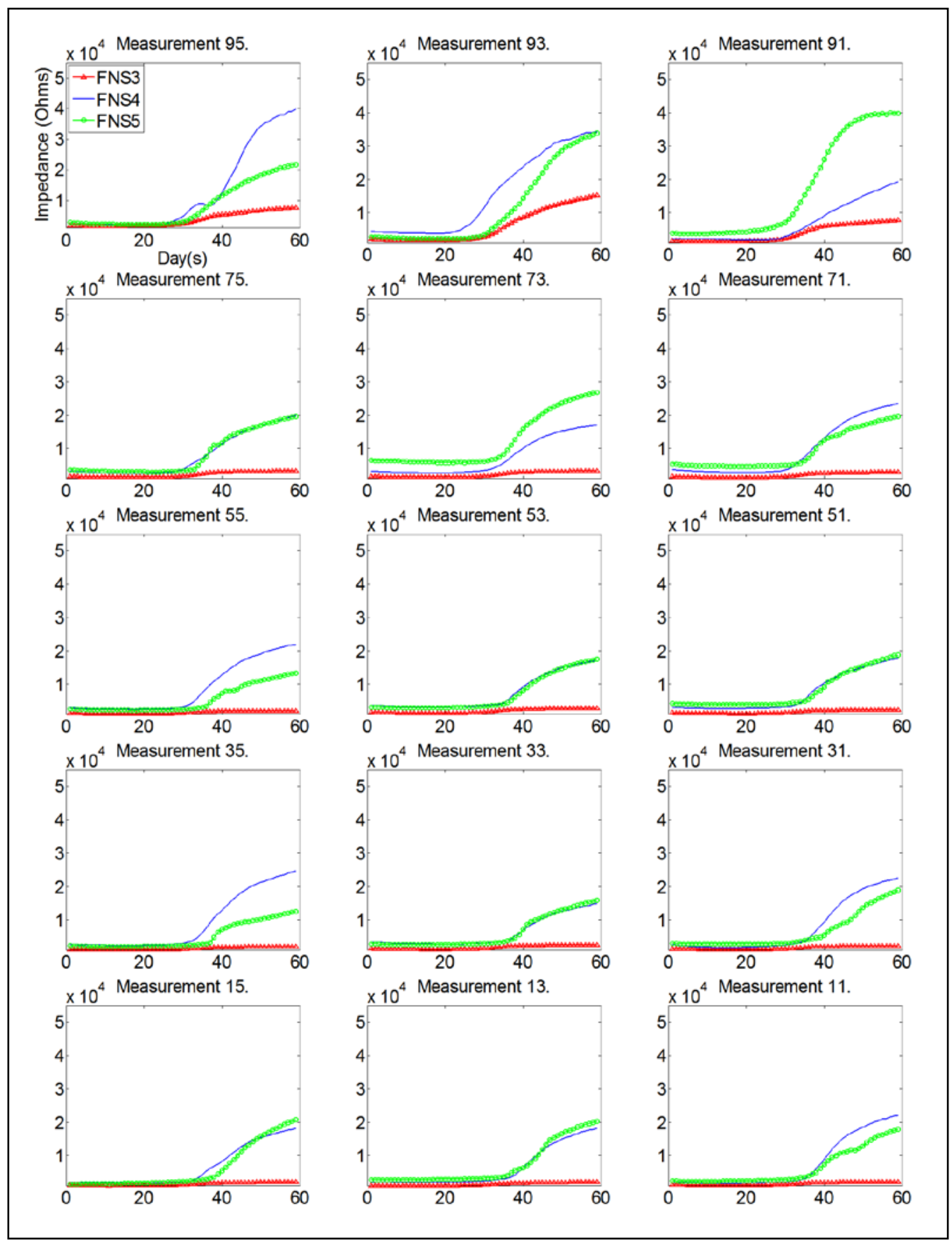

Figure 16: Plots of measured impedance $(\Omega)$ against time (days) in Test 2 for FNS3, 4 and 5 for for selected measurement pairings. 


\section{SUMMARY}

The potential for using measurements of electrical impedance to determine the changing distribution of water in soil due to the growth of roots has been explored. Such information might inform, for instance, crop breeding programmes. Capacitively-coupled contactless conductivity (C4D) electrodes have been employed in order to reduce electrochemical effects that typically arise when metal electrodes are in intimate contact with the soil. Such effects alter the measurements due to the effect of contact impedance and can lead to catastrophic failure due to corrosion.

Tests using parallel plate cells verify the analytical model that is proposed. Consideration of measurements on soil, as a function of moisture content, compaction and temperature, reveal that moisture has the most significant influence on the measured impedance. As moisture levels increase the impedance decreases and the most notable changes occur in dry soil. Compaction of the soil produces changes in the measured impedance. The effect is relatively insignificant compared to soil moisture under dry conditions but becomes comparable when the soil is wet. The observed temperature fraction dependence of $2 \% /{ }^{\circ} \mathrm{C}$ is in agreement with previous reports and can be calibrated out of the measurements.

Measurements were made on laboratory-scale rhizotrons housing growing maize plants. Results were compared to those using a control vessel containing only soil. Measurements from the $10 \times 6$ electrode arrays reveal changes in the impedance measurements that have been correlated with the water uptake due to the growth of the plants from qualitative visual inspection and post-test gravimetric analysis. Changes in the control vessel are much smaller than those in the growth vessels and, despite precautions, it is likely that these are due to evaporation.

In conclusion the technique shows potential for providing live estimates of the water distribution in the root zone. Due to difficulties presented by the inherent inhomogeneities of soil the relationship between the impedance measurements and the water content is relative. In addition, effects due to compaction and temperature must be considered. Measurement of temperature is straightforward and allows straightforward calibration. Deployment would require control measurements on regions that do not contain growing plants in order to provide calibration.

\section{ACKNOWLEDGEMENTS}

We would like to thank the Engineering and Physical Sciences Research Council (EPSRC) of the UK for a studentship for PN and for funding under a Knowledge Transfer Account held at the University of Manchester. 


\section{REFERENCES}

Amin, M.H.G., Chorley, R.J., Richards, K.S., Bache, B.W., Hall, L.D. and Carpenter, T.A. Spatial And Temporal Mapping Of Water In Soil By Magnetic Resonance Imaging. Hydrological Processes, 1993. 7(3): P. 279-286.

Anderson, S.H., Peyton, R.L., Wigger, J.W., Gantzer, C.J. Influence Of Aggregate Size On Solute Transport As Measured Using Computed Tomography. Geoderma, 1992. 53(3-4): P. 387-398.

Barker, R.D. The Offset System Of Electrical Resistivity Sounding And Its Use With A Multicore Cable. Geophysical Prospecting, 1981. 29, 128-143.

Binley, A., Henry-Poulter, S., and Shaw, B. Examination Of Solute Transport In An Undisturbed Soil Column Using Electrical Resistance Tomography. Water Resour. Res., 1996. 32(4): P. 763-769.

Binley, A., Winship, P., Middleton, R., Pokar, M., and West, J. High-Resolution Characterization Of Vadose Zone Dynamics Using Cross-Borehole Radar. Water Resour. Res., 2001. 37(11): P. 26392652.

Brady, N.C., The Nature And Properties Of Soils. 8th Edition Ed. 1974: Macmillan Publishing Co. Bungard, 2013. Laminat Lotstop Dry Film Solder Mask, Bungard Elektronik GmbH

Busch, J., Mendelssohn, I.A, Lorenzen, B., Brix, H. And Miao. S. A Rhizotron To Study Root Growth Under Flooded Conditions Tested With Two Wetland Cyperaceae. Flora, 201:429-439, 2006.

Chang Seop, K., Min-Kyu, K., Hyun-Kyo, J., Song-yop, H., and Baek-soo, S., Electric Resistivity Tomography For Geophysical Inverse Problems, IEEE Transactions on Magnetics, 1997. 33(2): P. 1852-1855.

Dahlin, T. 1996. 2d Resistivity Surveying For Environmental And Engineering Applications. First Break, 14.

Fracassi Da Silva, J.A. \& Do Lago, C.L. 1998. An Oscillometric Detector For Capillary Electrophoresis, Analytical Chemistry, 70, 4339-4343.

Gas, B., Demjanenko, M. \& Vacík, J. 1980. High-Frequency Contactless Conductivity Detection In Isotachophoresis. Journal Of Chromatography A, 192, 253-257.

Greve, A.K., Acworth, R.I., and Kelly, B.F.J. Detection Of Subsurface Soil Cracks By Vertical Anisotropy Profiles Of Apparent Electrical Resistivity. Geophysics, 2010. 75(4): P. Wa85-93.

Hedberg, S.A., Knight, R.J., MacKay, A.L., and Whittall, K.P. The Use Of Nuclear Magnetic Resonance For Studying And Detecting Hydrocarbon Contaminants In Porous Rocks. Water Resour. Res., 1993. 29(4): P. 1163-1170.

Herman, R., An Introduction To Electrical Resistivity In Geophysics. American Journal Of Physics, 2001. 69(9).

James, B.R., Bartlett, R.J., \& Amadon, J.F. (1985). A Root Observation And Sampling Chamber (Rhizotron) For Pot Studies. Plant And Soil, 85(2), 291-293.

Loke, M. 2001. Tutorial: 2-D and 3-D Electrical Imaging Surveys. Geotomo Software, Malaysia.

Luo, L.F., Lin, H., and Halleck, P. Quantifying Soil Structure And Preferential Flow In Intact Soil Using X-Ray Computed Tomography. Soil Science Society Of America Journal, 2008. 72(4): P. 1058-1069.

Newill P., Karadaglić D., Podd F., Grieve B.D., Staerkle M, Leipner J.,Screpanti C. and York T.A., 2013, Electrical Impedance Imaging of the Root Zone, $7^{\text {th }}$ World Congress on Industrial Process Tomography, Krakow, Poland, Sept. 2-5, 142-148. (ISBN: 978085316323 7)

Smith, R.L, 1993. Electrical measurements of soils with alternating currents. Journal of the Institution of Electrical Engineers. 75;452 
Szarka, L., Geophysical Mapping By Stationary Electric And Magnetic Field Components: A Combination Of Potential Gradient Mapping And Magnetometric Resistivity (MMR) Methods. Geophysical Prospecting, 1987. 35(4): P. 424-444.

Taylor, H.M., Upchurch, D.R., McMichael, B.L. Applications and limitations of rhizotrons and minirhizotrons for root studies. Beltsville Symposia in Agricultural Research Volume 14, 1991, pp 9197.

Topp, G. C., Davis, J. L. \& Annan, A. P. 1980. Electromagnetic determination of soil water content: Measurements in coaxial transmission lines. Water Resource Res., 16, 574-582.

Wang, B., Hu Y., Ji H., Huang, Z., and Li, H., A Novel Electrical Resistance Tomography System Based On C4d Technique, IEEE Instrumentation and Measurement Technology Conference, 2012, Vol., No., Pp.1929,1932, 13-16 May 2012.

White, R.E., Introduction To The Principles And Practice Of Soil Science. 1979: Blackwell Scientific Publications.

York T.A., Davidson J.L., Mazurkiewich L., Mann R. and Grieve B.D., "Towards Process Tomography for Monitoring Pressure Filtration”, IEEE Sensors Journal, 5,2, 2005, 139-152

Zimmermann E., Kemna A., BerwixJ., Glaas W. and Vereecken H., "EIT measurement system with high phase accuracy for the imaging of spectral induced polarization properties of soils and sediments", Measurement Science and Technology, 19, 9, 2008, [doi:10.1088/09570233/19/9/094010]

Zimmermann E., Kemna A., BerwixJ., Glaas W., VereeckenH. Münch H.M. and Huisman J.A., "A highaccuracy impedance spectrometer for measuring sediments with low polarizability", Measurement Science and Technology, 19, 10, 2008, [doi:10.1088/0957-0233/19/10/105603] 